\title{
La Red Feminista Quintanarroense y la toma pacífica del Congreso del Estado de Quintana Roo
}

\author{
The Quintana Roo Feminist Network and the Peaceful \\ Takeover of the Quintana Roo State Congress
}

Fecha de recepción: 08/09/2021

Fecha de aceptación: 29/11/2021

Fecha de publicación: 07/03/2022

https://doi.org/10.48102/if.2022.v2.n1.205

\section{Yunitzilim Rodríguez Pedraza*}

yunitzilim@uqroo.edu.mx; yunitzilim@outlook.com

ORCID: https://orcid.org/0000-0002-7329-2169

Doctora en Derecho Constitucional y Amparo

Universidad de Quintana Roo

México

\author{
Erika Lizbeth Cornelio Ramos** \\ erika_kornelio@hotmail.com \\ Maestra en Políticas Públicas Comparadas \\ Universidad Modelo de Chetumal \\ México
}

\begin{abstract}
* Yunitzilim Rodríguez Pedraza es profesora investigadora de tiempo completo de la Academia de Ciencias Jurídicas de la División de Ciencias Sociales y Derecho de la Universidad de Quintana Roo (UQROO). Licenciada en Derecho por la UQROO, maestra en Derecho Constitucional y Amparo por la Universidad Iberoamericana Campus Golfo Centro y doctora en Derecho por la Universidad Popular Autónoma de Veracruz. Candidata a Investigadora del Sistema Nacional de Investigadores (SNI). Sus líneas de investigación son: derechos humanos, género, Estado y seguridad pública.

** Erika Lizbeth Cornelio Ramos es catedrática en la Universidad Modelo de Chetumal. Licenciada en Relaciones Internacionales por la Universidad de Quintana Roo (UQROO) y maestra en Políticas Públicas Comparadas por la Facultad Latinoamericana de Ciencias Sociales (FLACSO); actualmente, cursa la licenciatura en Derecho en la Universidad Autónoma de Chiapas (UNACH). Sus líneas de investigación son: enfoque de género, políticas públicas y derechos humanos.
\end{abstract}




\author{
Sandra María Guadalupe Cortés González*** \\ sandracortes0808@gmail.com \\ Licenciada en Derecho \\ Colectiva Marea Verde Quintana Roo \\ y Red Feminista Quintanarroense \\ México
}

\title{
Resumen
}

La toma pacífica del Congreso del Estado de Quintana Roo es un hecho histórico. Mujeres organizadas articuladas bajo la Red Feminista Quintanarroense levantaron la voz y pusieron el cuerpo durante 95 días en plena pandemia por el virus COVID-19 -46 de ellos sin energía eléctrica ni suministro de aguapara exigir que se legislara sobre su derecho a decidir. Las autoridades, demostrando su poca formación en materia de perspectiva de género, derechos humanos y, específicamente, en lo que implica el derecho a la protesta pacífica, incentivaron el discurso de odio e intolerancia que de por sí ya existía en contra de las feministas, especialmente en contra de aquéllas que se posicionaban abiertamente a favor del aborto legal, seguro y gratuito.

No obstante, el movimiento cobró fuerza y logró que se designara una sede alterna para que la "Legislatura de la Paridad" sesionara y que se modificara el calendario establecido para la discusión de las iniciativas existentes respecto a la despenalización del aborto; también logró un dictamen positivo sobre la materia y evidenció claramente que el discurso político sobre la lucha para erradicar la violencia contra la mujer en el estado y en el país es una simulación.

\section{Palabras clave}

Aborto legal, derecho de protesta, criminalización a feministas, laicidad, derecho a decidir.

*** Sandra María Guadalupe Cortés González es integrante de la colectiva Marea Verde Quintana Roo y de la Red Feminista Quintanarroense. Licenciada en Derecho por la Universidad de Quintana Roo (UQROO). Activista, promotora y defensora de los derechos humanos de las mujeres; acompañante en atención jurídica. Dentro de la colectiva Marea Verde Quintana Roo, en 2018, redactó la "Iniciativa de Decreto por el que se reforman, adicionan y derogan diversas disposiciones de la Constitución Política del Estado Libre y Soberano de Quintana Roo; el Código Penal para el Estado Libre y Soberano de Quintana Roo; y la Ley de Salud del Estado de Quintana Roo", primera iniciativa ciudadana presentada en el Congreso del estado con el propósito de lograr la interrupción del embarazo sin penalización hasta antes de la decimosegunda semana de gestación. Actualmente realiza acompañamiento y canalización a víctimas, así como socialización de los derechos humanos de las mujeres. 


\section{Abstract}

The peaceful takeover of the Congress of the State of Quintana Roo is a historical fact. Organized women articulated under the Quintanarroense Feminist Network, raised their voices, and put their bodies together for 95 days in the midst of the COVID-19 virus pandemic -46 of them without electricity or water supply - to demand legislation on their right to decide. The authorities, demonstrating their lack of training in matters of gender perspective, human rights and specifically regarding what the right to peaceful protest implies, encouraged hate speech and intolerance that already existed against feminists and especially against those who were openly in favor of legal, safe and free abortion.

But the movement gained strength and managed not only to designate an alternate headquarters for the "Parity Legislature" to meet and also modify the calendar established for the discussion of existing initiatives regarding the decriminalization of abortion, it also achieved a positive ruling on the matter and clearly evidenced that the political discourse on the fight to eradicate violence against women in the state and in the country is a simulation.

\section{Keywords}

Legal abortion, right of protest, criminalization of feminists, secularism, right to decide.

\section{Introducción}

La Red Feminista Quintanarroense (RFQ) representa una articulación de colectivas y organizaciones de la sociedad civil conformadas por mujeres que han trabajado desde diversos espacios a favor de los derechos de las mujeres y niñas en la entidad. Dada la ubicación de Quintana Roo en el sureste y el Caribe mexicano, la población se conforma por mujeres que proceden de diversas entidades y países que se asumen latinas o caribeñas; otras, además, se identifican o autodenominan indígenas, afromexicanas o afrodescendientes.

En esta entidad ubicada en el sureste mexicano, se movilizan las mujeres de la RFQ, quienes impulsan la lucha y se han fortalecido desde el sur y desde sus realidades sociales, económicas y culturales. Una de las aportaciones de la RFQ es que propicia el movimiento feminista desde las periferias y descentralizado de la Ciudad de México. Históricamente, 
el feminismo en México se ha pensado desde el centro, no desde la periferia y mucho menos desde los estados frontera. Por ello, la lucha desde el sur de México ha marcado precedente y es histórica.

El movimiento feminista en Quintana Roo jamás había tenido tanta visibilidad como en los últimos cuatro años, no porque no existiera, sino porque alcanzó relevancia nacional e internacional con los vuelcos a las calles de miles de mujeres, especialmente jóvenes, que salieron a exigir un alto a la violencia ejercida de diversas formas contra las mujeres, pese a las condiciones económicas y políticas de la población de la entidad que aparentemente no eran propicias para el surgimiento de un movimiento con capacidad de mover a miles de mujeres.

El 28 de septiembre de 2018 es una fecha que ha quedado marcada en la historia de la lucha por el derecho a decidir en la entidad, pues señala el inicio de este movimiento articulado que impulsó la marea verde en Quintana Roo. El movimiento cuenta con la participación de mujeres de todos los estratos sociales - muchas de ellas profesionistas-, preparadas en el tema, empáticas, sororas, ${ }^{1}$ con objetivos firmes y con el hartazgo de luchar desde la individualidad. Se inició así la lucha en el Congreso del Estado de Quintana Roo con la primera marcha en la que las quintanarroenses salieron a las calles a levantar la voz, a hablar del aborto, del derecho a decidir, de la educación integral de la sexualidad; se visibilizaron las necesidades sobre los derechos sexuales y reproductivos de las mujeres del sur. Esto fue un momento fundamental en la capital quintanarroense puesto que las mujeres, en lo general, jamás se habían organizado para exigir y hacer visibles sus derechos, lo que continuó en el 2019, año en el que se notó mayor participación que en 2018.

En 2019, se observaron las primeras marchas del 8 de marzo con miles de mujeres, ahora ya con mejor organización y con mayor fortaleza. A principios de 2020, comenzaron las primeras articulaciones a nivel

1 La antropóloga mexicana Marcela Lagarde es la principal referente actual al hablar de sororidad, que define como "una dimensión ética, política y práctica del feminismo contemporáneo. Es una experiencia de las mujeres que conduce a la búsqueda de relaciones positivas y la alianza existencial y política, cuerpo a cuerpo, subjetividad a subjetividad con otras mujeres, para contribuir con acciones específicas a la eliminación social de todas formas de opresión y al apoyo mutuo para lograr el poderío genérico de todas y el empoderamiento vital de cada mujer" (Lagarde, 2006, p. 126). 
estatal no sólo con la marea verde sino con todas las colectivas que luchaban contra las diversas violencias que atravesaban a las mujeres en todos los espacios.

En 2020, por primera vez, se gestó una organización estatal entre colectivas para identificarse, unir esfuerzos, crear redes de apoyo y, sobre todo, generar agenda sobre la despenalización del aborto y posicionar e impulsar el tema. Con esta agenda, comenzó de forma alterna un acercamiento con las instituciones de manera articulada para atender todas las problemáticas que enfrentaban las mujeres, las cuales se potenciaron por la pandemia de COVID-19; se realizaron una serie de mesas de trabajo en línea para avanzar en mejorar la atención, investigación y sanción de dichas violencias.

No obstante, lo que catalizó la coordinación y articulación de las colectivas fue el llamado 9N (9 de noviembre). Tras el ataque del que fueron objeto mujeres y hombres que marchaban por el feminicidio de Alexis $^{2}-\mathrm{el}$ cual había ocurrido un fin de semana antes en Cancún, Quintana Roo-, las colectivas feministas coincidieron en que lo más importante era consolidar una red, a la que llamaron Red Feminista Quintanarroense. La RFQ tenía el objetivo de dialogar con las autoridades y establecer una serie de exigencias al Estado para la erradicación de la violencia feminicida en Quintana Roo, aunado a una serie de peticiones que quedaron plasmadas en el pliego petitorio que entregaron en su primera reunión con el Ejecutivo del estado, el gobernador Carlos Joaquín González, el 16 de noviembre de 2020.

Una vez articuladas esa primera reunión y la serie de exigencias establecidas en cincuenta y cuatro puntos del pliego petitorio - entre ellas, la solicitud de renuncia del secretario de Seguridad Pública, el alto a los feminicidios con políticas públicas concretas, atender la despenalización del aborto y detener la intención de establecer el pin parental en la ley de

2 Bianca Alejandrina Lorenzana Alvarado, de veinte años, salió de su casa el 7 de noviembre de 2020. Tras la denuncia de su desaparición, las autoridades activaron el Protocolo Alba. Sin embargo, su cuerpo fue hallado un día después. El 9 de noviembre, "colectivos feministas convocaron a una manifestación para exigir justicia por ella y por todas las mujeres que han sido asesinadas. La manifestación se realizó el lunes por la tarde, primero ante la Fiscalía General del Estado y posteriormente en el palacio municipal de Benito Juárez. Durante las protestas, policías de Benito Juárez dispararon a los manifestantes, lo que dejó al menos cuatro personas heridas, entre ellas dos periodistas que cubrían la manifestación" (Milenio Digital, 2020). 
educación (Palco Noticias, 2020)-, se logró visibilizar la existencia de la RFQ y de la lucha feminista, lo que nunca antes había pasado pues no se les consideraba para ninguna decisión, política o estrategia de gobierno.

A partir de entonces, se acordó una organización interna entre colectivas. El 25 de noviembre, fecha en la que se conmemora el Día Internacional de la Eliminación de la Violencia contra la Mujer, efectuaron un plantón en la explanada del Congreso del Estado de Quintana Roo, cansadas de la omisión de la Legislatura para legislar el reconocimiento, respeto y garantía del derecho a decidir de las mujeres. Durante el evento, se colocó una "Antimonumenta" para que quedara evidencia de la lucha y de la falta de voluntad política para erradicar la violencia de género a pesar de contar con una Declaratoria de Alerta de Violencia de Género contra las Mujeres en el estado desde el 7 de julio de 2017.

La toma del Congreso del Estado de Quintana Roo no era parte de las actividades organizadas por la RFQ. En el proceso organizacional del plantón afuera del Congreso y de la colocación de la Antimonumenta, la toma fue un hecho circunstancial, consecuencia de la invisibilización de la lucha, del propio plantón y de las vulneraciones a las que fueron expuestas las mujeres que lo sostenían. Fue así como, el viernes 27 de noviembre de 2020 por la noche, el Congreso fue tomado pacíficamente, marcando un hito en la lucha feminista de la ciudad, la entidad y el país.

En el presente artículo, se realizará un recorrido por los hechos previos que llevaron a la toma pacífica del Congreso, así como los obstáculos, represiones, avances, acuerdos y cierre que tuvo ese hecho histórico sostenido por mujeres feministas, activistas y defensoras de derechos humanos que lograron poner el tema del derecho a decidir en la agenda legislativa.

Para ello, se deja evidencia de la observación participante de las autoras del presente artículo y del diario de campo registrado en la relatoría de hechos elaborada por la Red Feminista Quintanarroense durante los días de la toma.

\section{El $9 \mathrm{~N}$}

Ante los hechos del 9N, el 16 de noviembre de 2020, la RFQ presentó un pliego de peticiones a los tres poderes del estado en el que, de manera enunciativa más no limitativa, señalaron cincuenta y cuatro puntos que requerían implementarse -no sólo con voluntad política sino también con recursospara lograr cambios estructurales en favor de los derechos de las mujeres y 
niñas. Entre los puntos planteados, se encontraban diez acciones legislativas concretas; entre ellas, la urgente discusión y análisis de las iniciativas en torno a la despenalización del aborto (Varillas, 2020).

Asimismo, el pliego contenía un apartado sobre los derechos sexuales y reproductivos - del punto 38 al 43- en el que señalaban la necesidad del respeto a la laicidad, de la educación integral de la sexualidad, del suministro de métodos anticonceptivos en los centros de salud rurales y urbanos y de la capacitación y observancia de la Norma Oficial Mexicana NOM-046-SSA-2005 para detener la criminalización de las mujeres que deciden sobre sus cuerpos.

Tras la sistemática omisión y negativa de los y las legisladoras integrantes de las comisiones a las que fueron turnadas las iniciativas a favor de la despenalización del aborto, las feministas decidieron realizar acciones directas para visibilizar la causa y la lucha. Por ello, con motivo del Día Internacional de la Eliminación de la Violencia contra la Mujer, organizaron movilizaciones pacíficas en varios municipios del estado. En Chetumal, la capital de Quintana Roo, convocaron a una concentración que concluyó con la lectura de un pronunciamiento en el que informaron que instalarían un plantón en la plazoleta del Congreso desde ese día, 25 de noviembre (Maldonado et al., 2020).

\section{Causas de la toma pacífica}

El 27 de noviembre en la noche, el plantón se convirtió en una toma y ocupación pacífica de las instalaciones del Congreso que son de acceso público (el vestíbulo del edificio y los sanitarios) dadas las siguientes circunstancias:

a. Durante la noche del día 25 -cuando se instaló el plantón-, todo el día 26 y el día 27 de noviembre de 2020 hasta antes de las 20:00 horas, no hubo interés ni comunicación alguna con las feministas por parte de las y los legisladores para trabajar sobre la ruta legislativa a emprender para dar atención a las diez acciones legislativas que planteaban como principal exigencia.

b. Durante la noche del día 25 de noviembre, los guardias de seguridad pusieron música a alto volumen, a pesar de que muchas de ellas intentaban dormir mientras otras hacían la vigilia; al pedirles que bajaran el volumen, incluso le subieron más, en un intento de hostigar e incluso de privar del sueño a quienes participaban en el plantón. 
c. Las dos noches que pernoctaron afuera (la del 25 y la del 26 de noviembre), les permitieron el acceso a los sanitarios; sin embargo, varias compañeras fueron víctimas de acoso por parte del personal de seguridad puesto que sólo las dejaban pasar de una en una.

d. El día viernes 27 de noviembre, unos quince minutos antes de las 20:00 horas, una mujer, familiar de una víctima de feminicidio que participaba en las actividades, pidió acceder al baño y los guardias le dijeron que se apurara porque a las 20:00 horas cerraban y no se iba a quedar nadie ahí; la señora se acercó a informar de ello a las compañeras; uno de los guardias también se acercó a confirmar la información.

e. Le solicitaron al guardia que les dieran oportunidad de contactar a algunas diputadas o diputados para que se continuara proporcionando ese servicio que resultaba esencial; además, garantizaba el ejercicio de las medidas de prevención de COVID-19 como es la higiene de manos.

f. Enseguida, varias de ellas empezaron a escribirle y marcarle a las y los diputados para pedirles que intervinieran; sin embargo, no recibieron respuesta alguna; mientras tanto, lo que hizo el personal de seguridad fue irse de la plazoleta hacia las puertas de acceso al Congreso y empezaron a cerrarlas, por lo que las mujeres que sostenían el plantón decidieron no permitirlo e ingresaron al vestíbulo del Congreso para así tener acceso a los sanitarios, además de poder resguardarse de la lluvia que en ese momento había iniciado. g. La toma se transmitió en vivo por la página oficial de Marea Verde Quintana Roo, lo que se convirtió en un llamado a todas las demás compañeras, quienes se acercaron apenas pudieron o apoyaron el acto a través de esa red social.

h. En el interior del edificio, se quedaron seis elementos de seguridad del Congreso, todos del sexo masculino, quienes se negaron a salir de él. (R. Pedraza, Registro de diario de campo durante la toma pacífica de "la Congresa", 27 de noviembre de 2020)

Momentos después, esa misma noche del 27 de noviembre, el presidente de la Junta de Gobierno y Coordinación Política del Congreso, el diputado Erick Gustavo Miranda García, envío a un empleado de nombre Benjamín Vaca González para amedrentarlas; Vaca tuvo una conducta por 
demás grosera pues, al decirle que no podía entrar - puesto que ya se había efectuado la toma del Congreso y la idea era que salieran los hombres de seguridad y no que entraran más-, dijo: "a mí me dejas entrar porque éste es mi edificio y cuidadito le hacen algo al mural porque va a haber consecuencias" (B. Vaca, Comunicación personal, 27 de noviembre 2021), por lo que la comunicación con él no pudo darse.

Esa misma noche, ya estando dentro de las instalaciones del Congreso y dado que entre las mujeres que efectuaban la toma había víctimas de delitos sexuales, se le solicitó al personal de seguridad (todos hombres) que se retiraran del edificio; éstos se negaron rotundamente y empezaron a tomar capturas fotográficas de la identidad de las feministas que estaban presentes, fotos que empezaron a circular en grupos de Facebook. Ellas fueron informadas de este acto por personas aliadas.

Después de sostener dos llamadas telefónicas con el diputado Erick Gustavo Miranda García, éste manifestó su amplia preocupación por el mural que se encuentra en el vestíbulo del Congreso y se negó a pedir a su personal masculino que se retirara; incluso se le planteó que podría sustituirlo con personal femenino para garantizar que hubiera vigilancia pero que la misma no fuese amedrentadora para las participantes.

Se insistió en exigir que se garantizara la seguridad para las manifestantes y defensoras de derechos humanos en la toma, en contra de cualquier acto de acoso o agresión de índole sexual o de otra acción que pudiera menoscabar la integridad de las manifestantes, por lo que ellas se mantuvieron firmes en la postura de no permitir hombres en el vestíbulo del Congreso, que era el espacio en donde iban a dormir y en donde mantendrían el acto político de protesta pacífica.

Posteriormente, llegó una comitiva de mujeres trabajadoras y directivas del Congreso, quienes nos propusieron ingresar para garantizar que el mural no fuera afectado y, además, para ser el enlace de comunicación y negociación con nosotras; dicha comitiva estuvo encabezada por la diputada Ana Pamplona Ramírez -legisladora que el 9 de marzo de 2020 había ingresado una de las cuatro iniciativas a favor de la despenalización-. Se expuso ante el grupo de trabajadoras y la diputada la situación que se presentó, la falta de comunicación por parte del Congreso, cuáles eran nuestras peticiones, así como la necesidad de que los veinticinco legisladores y legisladoras dejaran de invisibilizar la lucha y de hacer a un lado la discusión sobre los derechos sexuales y reproductivos; se les solicitó que, a través de su 
conducto, les dijeran a todas las y los diputados que los estarían esperando en el Congreso para hablar de sus exigencias, después de casi tres días de invisibilizar el plantón.

Las peticiones específicas que se plantearon antes del plantón y en la toma fueron:

1. Que se analicen, discutan y dictaminen las iniciativas en favor de la despenalización del aborto, especialmente la última, que era la única vigente y que fue canalizada a las comisiones de Justicia y Salud.

2. Que se elabore una ruta legislativa respecto de los nueve puntos restantes señalados como acciones legislativas en el pliego petitorio entregado el día 16 de noviembre.

En virtud del riesgo evidente en el que se encontraban como defensoras de derechos humanos, especialmente con el antecedente de represión violenta de otra protesta feminista sólo unos días antes (el 9N), se pidió la intervención de la Comisión de los Derechos Humanos del Estado de Quintana Roo (CDHEQROO), la cual emitió las medidas precautorias y cautelares derivadas del expediente VG/OPB/402/11/2020, en el que se solicitaba al presidente de la Junta de Gobierno y Coordinación Política de la XVI Legislatura (JUGOCOPO) que girara sus instrucciones para que, de manera inmediata, se adoptaran medidas precautorias en favor de las mujeres manifestantes en el Congreso, a efecto de respetar su derecho a la libertad de expresión, a la integridad y a la seguridad jurídica, así como para asegurar que no se les impidiera el acceso a los lugares públicos del recinto en donde realizaban la manifestación (como el vestíbulo y los baños); también se indicaba que debía instruir al personal para garantizar el respeto a la integridad física y psicológica de las manifestantes, así como suspender y evitar la aplicación de cualquier medida que violentara sus derechos humanos.

El 1 de diciembre, el Consejo Consultivo de la Comisión de Derechos Humanos del Estado de Quintana Roo, compuesto por el presidente de la Comisión y por personas independientes y expertas en materia de derechos humanos, emitió un comunicado de respaldo a la regulación de los derechos sexuales y reproductivos de las mujeres en Quintana Roo (Consejo Consultivo de la CDHEQROO, 2020). 


\section{Sede alterna de la XVI Legislatura}

A pesar de la apertura al diálogo de la RFQ, las manifestantes no cedieron en el pliego petitorio; pernoctaron y permanecieron varios días en el vestíbulo del Congreso. Las y los legisladores, con la certeza de que no se daría ni un sólo paso atrás, designaron una sede alterna en el siguiente sentido:

A través de una iniciativa, la XVI Legislatura de Quintana Roo designó al Centro de Convenciones de Chetumal como la sede alterna para sesionar y así respetar la Ley Orgánica del Poder Legislativo del Artículo 61 y acatar las medidas cautelares emitidas por la Comisión de los Derechos Humanos del Estado. (El Quintana Roo MX, 2020)

\section{Los antiderechos}

Los grupos antiderechos estaban activos y eran incentivados principalmente por organizaciones religiosas. Grupos eclesiásticos convocaron una manifestación en las instalaciones del Congreso el día 8 de diciembre para oponerse a la propuesta de regular los derechos sexuales y reproductivos de mujeres y niñas. En el marco de dicha convocatoria, integrantes de la RFQ comenzaron a recibir amenazas y agresiones a través de redes sociales, las cuales incluían insultos, descalificaciones y llamados al ejercicio de la violencia en su contra.

El día 8 de diciembre, mientras acontecía la manifestación convocada por los grupos eclesiásticos, una de las compañeras más visible e identificada en la toma -y que había sido objeto específico de señalamiento en redes sociales- sufrió una agresión en su domicilio, la cual incluyó daños a su vehículo y el lanzamiento de un objeto inflamable al jardín de su hogar mientras su familia -incluyendo sus hijos - se encontraba en él. Por suerte, la rápida reacción de los vecinos logró apagar el conato de incendio y no se produjeron daños personales. Dichos hechos fueron denunciados ante la fiscalía pero aún no existen avances en la investigación. Al mismo tiempo, las agresiones y amenazas a través de medios digitales aumentaron en frecuencia y gravedad, tanto en contra de la RFQ como ataques individuales en contra de algunas integrantes.

9 de diciembre de 2020. Criminalización de la protesta y cuestionamiento a la CDHEQROO La página oficial del Congreso del Estado de Quintana Roo informó que el día 9 de diciembre de 2020 sesionarían las Comisiones Unidas, a efecto de 
iniciar la metodología para el análisis, estudio y discusión en Parlamento abierto de las iniciativas para la despenalización del aborto. Por ello, las colectivas y organizaciones de la RFQ se comunicaron formalmente con las diputadas y los diputados, reafirmado su apertura y disposición al diálogo constructivo, para solicitar que dicho proceso se efectuara de manera ágil y expedito para lograr de la mejor manera posible la pronta entrega de las instalaciones del Congreso. Señalaron, incluso, propuestas para permitir que las sesiones se pudieran realizar en el recinto del Congreso de manera segura, incluyendo medidas de mitigación de la COVID-19.

Ese mismo 9 de diciembre, fue citado a comparecer, en la sede alterna del Congreso, el presidente de la CDHEQROO. La comparecencia se usó para cuestionarlo y que rindiera cuentas sobre las medidas cautelares emitidas en favor de la integridad de las activistas y defensoras de los derechos humanos involucradas en la toma y sobre el comunicado emitido por el Consejo Consultivo de la Comisión.

Durante la comparecencia, las diputadas y diputados mostraron su desconocimiento sobre el derecho de reunión pacífica y sobre el papel de las instituciones ombudsperson; además, estigmatizaron y criminalizaron el movimiento feminista y a quienes se encontraban en la toma pacífica de las instalaciones del Congreso. En ningún momento, las diputadas y diputados expresaron su condena a la agresión sufrida por una de las compañeras en su casa el día anterior, ataque que puso en riesgo la vida y la integridad de su familia.

Entre lo afirmado por las diputadas y diputados frente al presidente de la CDHEQROO, se puede destacar lo siguiente:

a. Le recriminaron por haber emitido medidas cautelares y precautorias para asegurar la integridad de las defensoras de derechos humanos después de la toma del Congreso.

b. Lo acusaron de haber permitido que las defensoras de derechos humanos tomaran el Congreso.

c. Le cuestionaron los motivos y la legitimidad del Consejo Consultivo de la CDHEQROO para pronunciarse en favor de los derechos sexuales y reproductivos y la lucha feminista.

d. Con base en esas "acusaciones", plantearon la posibilidad de renuncia del ombudsperson del estado o la revocación de su mandato.

Rodríguez, Y., Cornelio, E. L. y Cortés, S. M. G. (2022). La Red Feminista Quintanarroense y la toma pacífica del Congreso del Estado de Quintana Roo. Iberoforum, Revista de Ciencias Sociales, Nueva Época, 2(1), 1-41, Artículos, e000205. https://doi.org/10.48102/if.2022.v2.n1.205

Licencia Pública Internacional - CC BY-NC-ND 4.0 
e. Invisibilizaron la lucha que se efectuaba a favor de los derechos humanos de las mujeres en el estado y estigmatizaron, señalaron y criminalizaron la lucha y la causa, cuestionando "las formas" y acusando a la protesta pacífica de ser violenta y vandálica.

f. Responsabilizaron a las feministas, activistas y defensoras de derechos humanos, durante casi todas las intervenciones que efectuaron, de que las y los trabajadores no pudieran ir al Congreso a trabajar; incluso aceptaron la explotación laboral que sufren las y los empleados al aceptar que algunos vivían en el Congreso, lo que hace suponer que no se cumplen con las condiciones generales de trabajo y además contravienen las disposiciones sanitarias con motivo de la pandemia.

g. Cuestionaron la autonomía de la CDHEQROO al señalar que, si no se resolvía el asunto de la toma del Congreso, le iban a pedir su renuncia.

h. Efectuaron actos directos de xenofobia en contra del personal de la Comisión.

i. Cuestionaron que personal de la CDHEQROO hubiera portado pañuelos verdes -símbolo de la lucha feminista en favor de los derechos sexuales y reproductivos-, como si fuera una situación que comprometiera el enfoque en derechos humanos, perspectiva de género e igualdad sustantiva con la que deben trabajar.

j. Demostraron una clara ignorancia del marco legal, funciones, alcances y documentos que expide la CDHEQROO, así como sobre los derechos humanos, lo que podría entenderse como una negación del derecho de reunión pacífica de otro grupo social, el cual está también protegido por los instrumentos internacionales.

$\mathrm{k}$. Intentaron contraponer los derechos humanos de las y los trabajadores de Congreso frente a los de las manifestantes, a pesar de señalar que nuestra causa era legítima. (Congreso del Estado de Quintana Roo, 2020)

Estos actos sin precedentes en la entidad dan una idea de la crisis de derechos humanos que existe en el país y, sobre todo, la subordinación que algunas personas creen que las Comisiones de Derechos Humanos tienen, olvidando que son órganos constitucionales autónomos y que dicha figura jurídica tiene un objeto específico. 
Debe recordarse que los órganos constitucionales autónomos se caracterizan por

la competencia para ejercer en grado supremo un complejo de funciones públicas; la idoneidad para frenar, controlar y equilibrar a los otros órganos con responsabilidades igualmente supremas; por lo tanto, la Constitución los coloca al menos en un lugar de relativa igualdad e independencia con respecto a estos órganos.

$[\ldots]$

los órganos constitucionales autónomos: "Tienen la gran ventaja de poder decidir autónomamente su forma de gobierno o gobernanza corporativa, definir el conjunto de materias específicas de decisión, y las normas de procedimiento para validar la coerción institucional y técnica de las decisiones".

La autonomía, como se puede apreciar, es una forma de división de poderes, puesto que supone la distribución de funciones más allá de las tradicionales y de los órganos (soberanos) encargados de llevarlas a cabo. Por tanto, cada órgano autónomo se constituye en torno a una atribución y del área de competencia que se genera alrededor de ellos. Sin embargo, los órganos autónomos no están subordinados y no dependen de los órganos tradicionales, lo que implica una situación de independencia relativa. (Ruíz, 2017, pp. 87-88)

No debe permitirse que se cuestione la autonomía de un órgano constitucional autónomo y que las y los diputados crean que, por haber designado al presidente de la Comisión de Derechos Humanos - lo cual es su facultad y obligación-, la institución está bajo su orden y que el presidente o el órgano colegiado que lo conforma debe condicionar o supeditar su actuación a las aspiraciones y juicios de valor personales de las y los legisladores. Sin embargo, lastimosamente, eso pasó en Quintana Roo.

Cabe mencionar que ese mismo día, 9 de diciembre, sin importarle la toma pacífica ni el derecho de protesta que las feministas efectuaban con ella, el Pleno acordó, en sesión ordinaria, una agenda en la que el análisis, estudio y discusión en Parlamento abierto de las iniciativas para la despenalización del aborto se atenderían hasta el mes de febrero de $2021 \mathrm{y}$, llegado el caso, se dictaminarían hasta el mes de abril de ese mismo año. Esta resolución incumplía los compromisos previos de iniciar de inmediato 
el trabajo de análisis y dictaminación, invisibilizaba nuevamente la lucha y ponía en segundo plano los derechos sexuales y reproductivos de las mujeres en el estado.

Esa postergación hacía suponer que, probablemente, no se discutiría ni analizaría el punto dado que Quintana Roo tenía elecciones en 2021 y muchos diputados y diputadas contemplaban abandonar sus escaños para buscar otros puestos de elección; en este escenario, posicionarse en contra del tema ponía en entredicho sus candidaturas por lo que el establecimiento de esa agenda de discusión se veía como una táctica dilatoria.

En virtud del cuestionamiento y la limitación a los que fue sometido el presidente de la CDHEQROO, el 11 de diciembre se solicitó la intervención de la Comisión Nacional de los Derechos Humanos (CNDH) a fin de que, entre otros actos, actualizara las medidas precautorias y cautelares. Esta solicitud se entregó de manera personal el 14 de diciembre (Red Feminista Quintanarroense, 2020).

Derivado de las manifestaciones estigmatizantes en contra del movimiento, el 18 de diciembre de 2020, la RFQ presentó una queja formal ante la CNDH en contra de las y los legisladores del estado de Quintana Roo por discriminación y violencia institucional; sin embargo, hasta la fecha no ha habido respuesta o acción alguna en consecuencia.

Cabe señalar que, en simultaneidad con la toma pacífica del Congreso, las integrantes de la RFQ siguieron en las mesas de trabajo con el Ejecutivo estatal. Así, se reunieron con el gobernador el 15 de diciembre de 2020 para dar seguimiento al pliego petitorio entregado el 16 de noviembre. Esa reunión fue aprovechada para que la Oficina de la Alta Comisionada de las Naciones Unidas para los Derechos Humanos en México (ONU-DH) interviniera a favor del derecho de protesta y del respeto a la lucha que estaban sosteniendo las activistas, haciendo un reconocimiento de la causa.

Una de las notas periodísticas derivadas de dicha reunión refiere lo siguiente:

Ante la presencia virtual del Sr. Guillermo Fernández Maldonado, representante en México de la Alta Comisionada de las Naciones Unidas para los Derechos Humanos, el gobernador Carlos Joaquín presentó a la Red Feminista diez estrategias para dar seguimiento a los 54 puntos del pliego petitorio, entre las que se destacan: a) atención y reparación a víctimas; b) desarrollo de un presupuesto con perspectiva de del Congreso del Estado de Quintana Roo. Iberoforum, Revista de Ciencias Sociales, Nueva Época, 2(1), 1-41, Artículos, e000205. https://doi.org/10.48102/if.2022.v2.n1.205 Licencia Pública Internacional - CC BY-NC-ND 4.0 
género; c) creación de un programa único de capacitación; d) supervisión y transparencia participativa, entre otras. (Gobierno de Quintana Roo, 2020)

\section{La criminalización de la protesta}

Desde la toma, las activistas que participaron fueron víctimas de diversas acciones para debilitar la lucha; todas ellas constituyen actos de discriminación y represalias que, como servidores y servidoras públicas, las y los diputados efectuaron en contra del movimiento. Entre ellas, mencionamos las siguientes:

a. Las reiteradas amenazas emitidas de usar la fuerza pública para obligar a las manifestantes a dejar las instalaciones del Congreso del estado.

b. Desde el miércoles 2 de diciembre, las luces externas alrededor del Congreso y de la explanada no fueron encendidas; en consecuencia, la parte externa del lugar de la toma estuvo totalmente a obscuras, lo que las colocaba en estado de vulnerabilidad.

c. Apagaron el compresor, lo que afectó el funcionamiento óptimo del aire acondicionado. Éste se había mantenido prendido y funcionando siempre (situación que se pudo verificar puesto que, al ingresar a los sanitarios antes de la toma, incluso de madrugada, éste enfriaba adecuadamente); sin embargo, desde el día 2 de diciembre sólo expulsaba aire pero no enfriaba, lo cual afectó a un gran número de mujeres, niños, niñas, personas de la tercera edad y animales que se encontraban en el vestíbulo, ya que las manifestantes estaban imposibilitadas de abrir las puertas del recinto legislativo por temor a vulnerar la seguridad de la toma pacífica del Congreso. Además, el corte de la refrigeración afectó la conservación del mural que se encuentra en el vestíbulo del Congreso y por el que diversos diputados y diputadas mostraron gran preocupación de manera reiterada; ellas temían que fuera una táctica para que se generaran daños en el mural y posteriormente las responsabilizaran por éstos. 
d. El 4 de diciembre de 2020, se les suspendió el servicio de internet, lo que afectó el cumplimiento de las actividades escolares que debían efectuar las niñas y los niños que se encontraban con sus madres en la toma dado que, debido a la contingencia por COVID-19, las clases presenciales fueron suspendidas y las actividades escolares se realizaban de manera virtual.

e. En entrevistas otorgadas por las y los legisladores, éstos se refirieron a las manifestantes como chantajistas; también afirmaron que la toma era un capricho y omitieron mencionar que las activistas llevaban años efectuando diversas acciones y actividades, presentando escritos, oficios, exhortos a fin de lograr incentivar que legislaran sobre la garantía de los derechos sexuales y reproductivos de las mujeres y las niñas en el estado.

Una de las mayores represiones que sufrieron durante la toma se dio el 21 de diciembre de 2020 a las 13:00 horas, fue cortado el suministro de energía eléctrica del recinto legislativo. El corte fue hecho por la Comisión Federal de Electricidad (CFE) debido a que -según les fue referido- no se había pagado el servicio, pago a cargo del diputado Gustavo Miranda, presidente de la JUGOCOPO. El servicio no se reestableció a pesar de haber solicitado a la CNDH la emisión de nuevas medidas cautelares a favor de quienes sostenían la toma, lo que nunca sucedió.

La interrupción del suministro de energía eléctrica fue un acto que iba en contra de las medidas cautelares emitidas por la CDHEQROO, ya que, en la práctica, impidió el uso de los lugares públicos del edificio del Congreso, entre ellos los baños puesto que sin electricidad no funcionaban las bombas de agua, lo que afectó la higiene básica de mujeres, niñas y niños que permanecían en la toma e incrementó el riesgo de contagio de la COVID-19 debido a la imposibilidad de garantizar las medidas recomendadas por las autoridades sanitarias, como el lavado recurrente de manos. Esto atentó contra la integridad y el derecho a la protesta pacífica de las manifestantes dentro de la toma. La falta de energía eléctrica también impidió que los alimentos perecederos que las activistas tenían en refrigeración para alimentarse se mantuvieran en buen estado; asimismo, limitó su comunicación puesto que los equipos electrónicos (teléfonos y computadoras) no contaban con la carga suficiente para que pudieran mantenerse en contacto con el exterior. Artículos, e000205. https://doi.org/10.48102/if.2022.v2.n1.205 Licencia Pública Internacional - CC BY-NC-ND 4.0 
El corte de luz y agua, más allá de ser un acto de omisión administrativa, formó parte de la campaña de acoso institucional por parte del Poder legislativo hacia las defensoras de derechos humanos que se posicionaron a favor de los derechos sexuales y reproductivos de las mujeres y niñas en el estado. Ante estas agresiones, ellas iniciaron un acercamiento y diálogo con el Mecanismo Federal de Protección de Personas Defensoras de Derechos Humanos y Periodistas para la incorporación de la Red Feminista Quintanarroense al mismo. La RFQ fue incorporada el 23 de diciembre de 2020 y se emitió el plan de protección acordado por la Junta de Gobierno del Mecanismo los días 25 y 26 de febrero de 2021.

\section{El derecho de protesta y de manifestaciones pacíficas}

La ONU-DH México respaldó la lucha de la Red Feminista Quintanarroense y la toma pacífica del Congreso; incluso, se publicó un hilo en el perfil oficial de Twitter de la organización para reafirmar cuestiones elementales sobre el respeto al derecho de reunión pacífica y de manifestación en referencia a las acciones de la RFQ. Éstos son algunos de los tweets que conforman el hilo:

[2] El Consejo de Derechos Humanos de la ONU señala que "las manifestaciones pacíficas pueden contribuir al pleno disfrute de los derechos civiles, políticos, económicos, sociales y culturales".

[5] El Relator Especial sobre libertad de reunión pacífica y de asociación, señala que es "una congregación intencional y temporal de personas en un espacio privado o público con un propósito concreto" que puede adoptar diversas formas.

[6] Pueden ser manifestaciones, asambleas en locales, huelgas, procesiones, concentraciones, sentadas... para expresar reclamaciones, aspiraciones o celebraciones. Las protestas prolongadas también están protegidas por este derecho.

[8] Las protestas afectan actividades cotidianas, pero "este tipo de alteraciones son parte de la mecánica de una sociedad plural, donde conviven intereses diversos [...] que deben encontrar los espacios y canales mediante los cuales expresarse".

[9] La CIDH nos recuerda que la protesta es una forma de ejercicio de la libertad de expresión, el cual "no es un derecho más sino uno de 
los primeros y más importantes fundamentos de toda la estructura democrática".

[10] Las autoridades deben evitar interferencias ilegítimas con las protestas, proteger a quienes participan en protestas y a terceras personas, y abstenerse de descalificar o desanimar el ejercicio de este derecho.

[11] El Relator de libertad de reunión pacífica recuerda que "nadie debe ser penalizado ni debe recibir amenazas o sufrir violencia, acoso, persecución, intimidación o represalias por ejercer los derechos a la libertad de reunión pacífica". (ONU-DH México, 2020)

\section{Denuncias y negociaciones}

El 28 de diciembre de 2020, algunas de las activistas y defensoras de derechos humanos que se mantenían en la toma interpusieron una denuncia penal por el delito de discriminación y negligencia en el desempeño de función y cargo en contra de las y los veinticinco legisladores que conforman la XVI Legislatura, autonombrada la "Legislatura de la Paridad".

El 5 de enero de 2021, el gobernador del estado emitió un oficio para la Red Feminista Quintanarroense en el que adjuntó copia de otro oficio que se entregó al presidente de la JUGOCOPO para solicitar la reinstalación del suministro de energía eléctrica (Carrasco Fuentes, 2021).

El 11 de enero, el secretario de gobierno del estado de Quintana Roo, como enlace del Mecanismo de Protección de Defensoras de Derechos Humanos, emitió un nuevo oficio para el presidente de la JUGOCOPO en el que le propuso la instalación de una mesa de diálogo entre el Congreso del estado y la RFQ para escuchar y analizar propuestas para la solución del conflicto.

Estos dos oficios no tuvieron respuesta, lo que evidenció la simulación por parte del Ejecutivo y la nula voluntad política para resolver la problemática, emitiendo el mensaje de que a las defensoras de derechos humanos se les puede vulnerar sin que nadie, incluso el gobernador, pueda hacer nada.

El 12 de enero, el gobernador del estado de Quintana Roo asistió a la Sesión Solemne del 46 aniversario de la Promulgación de la Constitución en el Estado; en su discurso, se refirió a la situación de la toma e hizo un llamado a la Legislatura en el que reconoció que la sociedad está en conti- 
nuo cambio, en permanente transformación de pensamiento y renovación de ideas: "frente a estas realidades, no debemos temer a aquellas iniciativas que propugnen una renovación de las políticas sociales, económicas y culturales, siempre que se produzcan bajo el paraguas del estado de derecho, del pluralismo político y entre el respeto entre mayorías y minorías" (Congreso del Estado de Quintana Roo, 2020).

Ante ello, surgieron titulares como éste: "'Queremos acciones, no simulaciones': Ante omisión e incumplimiento de diputados, inunda la Red Feminista Quintanarroense transmisión de la sesión solemne de promulgación de la Constitución de QR"; en esta nota se resalta que "Por primera vez en la historia de Quintana Roo, la sesión solemne se realizó en un edificio alterno al Poder Legislativo ante la toma de la sede del Congreso por parte de la Red Feminista Quintanarroense" (Briceño, 2021).

También apareció otra nota titulada "Segunda llamada de Carlos Joaquín a diputados para atender demandas de grupos feministas", en la que se citaban palabras referidas por el gobernador:

En pleno respeto entre las mayorías y minorías y dentro el marco del derecho, los diputados locales deben trabajar sin miedo a las iniciativas que profundicen en los cambios sociales, económicos y culturales, como las que se refieren a la despenalización del aborto, promovidas y demandadas por grupos feministas. (EquilibrioDigital, 2021)

El 13 de enero de 2021, la RFQ presentó, ante la Dirección General de Atención Ciudadana de la Presidencia de la República, una solicitud para el presidente de la República a fin de lograr su intervención para detener los actos de represión en contra de quienes sostenían la toma y de quienes luchaban a favor de la causa, y para atender el pliego petitorio a favor de los derechos de las mujeres y niñas (Red Feminista Quintanarroense, 2021).

\section{Discurso de odio e intolerancia}

Se siguió incentivando el discurso de odio e intolerancia desde el Congreso del estado. El 15 de enero de 2021, el diputado Gustavo Miranda García, presidente de la JUGOCOPO, hizo una trasmisión en vivo desde su cuenta de Facebook con el título "Tema Acuerdo Feministas. Comenta qué harías tú con la situación de la luz en el Congreso" (Miranda, 
2021b); entre los señalamientos que hizo en dicha transmisión, destacan los siguientes:

- "hemos sido sumamente respetuosos, tal vez extremadamente respetuosos de emitir un comentario o emitir un posicionamiento [...] nos hemos mantenido al margen, siendo respetuosos, a pesar de todos los comentarios allá afuera, de los posicionamientos, etcétera".

- "Vamos a estar compartiendo una carta con la postura de parte de la XVI Legislatura, una postura personal".

Entonces no se entiende si es la postura de la XVI Legislatura o de él como servidor público y presidente de la JUGOCOPO.

- "No es nuestra obligación ni la obligación de los contribuyentes estar financiando ningún movimiento; por más justa que sea la causa, por más digna, por más real, no es la obligación de nosotros como ciudadanos estar pagando para que la gente se manifieste. ¿Qué es nuestra obligación como autoridad? Salvaguardar la integridad y sus derechos humanos, escucharles en todo momento, permitirles la libertad de expresión y bajo ninguna circunstancia agredirlas o hacer uso de la fuerza pública [...]. Sin embargo, no es nuestra obligación financiar o pagar la luz, y estar nosotros subsidiando los costos, porque es dinero de los contribuyentes".

- "En el diálogo se les solicitó al grupo de feministas que permitieran entrar al equipo de contabilidad a las oficinas del área contable [...] y al no permitirlo, pues no pudimos pagar la luz y CFE es quien paga [sic] la luz".

- "No está en las medidas cautelares de la Comisión de Derechos Humanos la obligación a pagarles la luz [...]; nosotros debemos de permitirles expresarse en el área del vestíbulo [...] donde se les está permitiendo expresarse y manifestarse [...] les hemos permitido manifestarse $[\ldots]$ no hemos hecho uso de la fuerza pública $[. .$.$] aunque$ han habido peticiones de otros actores en el estado, no lo hemos hecho ni lo vamos a hacer". 
En su transmisión, menciona abiertamente el nombre completo de dos compañeras que opinaron durante la emisión y señala que son parte de quienes estaban en la toma.

- "me he excedido con estas libertades [...] los primeros días que se les mantuvo el tema del aire acondicionado $[. .$.$] y la luz [\ldots]$ hasta que no pudimos por razones mayores pagar la luz".

Por último, llama a la ciudadanía a opinar:

- "Por favor, si son parte de la ciudadanía de Chetumal o de todo el estado, pongan sus comentarios, para saber qué opinión tienen, qué harían o cómo les gustaría que se trate este tema".

Las declaraciones vertidas por el servidor público incentivan aún más el discurso de odio e intolerancia hacia el movimiento y estigmatizan la lucha por el derecho a decidir; además, de manera específica, llama a la población a opinar sobre el tema, cuando antes ya refirió que no tiene por qué ser financiado por el Estado y menos con el dinero de los contribuyentes; asimismo, menciona a dos de las feministas que estaban en la toma, poniéndolas en el centro de los señalamientos.

El 18 de enero de 2021, a las 12:49, nuevamente el diputado Gustavo García Miranda, a través de su perfil de Facebook, trató públicamente el tema de la toma pacífica del Congreso (Miranda, 2021a). Las declaraciones que hizo fueron las siguientes:

- "Dentro de la causa, hay grupos verdaderos, pero hay un grupo político que se está aprovechando".

A partir del minuto 10:35, señala que, entre las feministas, hay intereses políticos; a pesar de que reconoce que hay grupos reales de mujeres que han sido víctimas, que se manifiestan, también apunta que

- "hay otro grupo [...] que se queda $24 / 7$, que para quedarse [...] con plantas de luz, con comida... pues hay un grupo financiando y cuando revisas los expedientes de gente que ha sido candidato o que pretende ser candidato o que milita en algún partido político y tiene comunica- 
ción directa con actores y servidores públicos actuales de otros poderes, pues te das cuenta que este tema tiene otros intereses políticos".

En el minuto 21:50 menciona:

- "Hasta que el diálogo no nos lo permita [...] no podemos hacer uso de la fuerza pública. Han habido peticiones de otros actores [...] pero no lo vamos a hacer porque, si así nos están [...] queriendo meter situaciones políticas, imagínense ustedes si hubiera un altercado" [en el Congreso].

A partir del minuto 18:10, señala otra vez que detrás del grupo de feministas hay

- "seguramente grupos ajenos al movimiento que somos parte de Morena, Verde y PT. Hay partidos involucrados atrás, hay quienes son afiliadas al PRI, quienes son afiliadas a otros partidos. Pudiera ser casualidad, pudiera no ser casualidad, pero creo que la misma gente local $[. .$.$] sabe por dónde viene eso".$

El 20 de enero de 2021, en el programa nocturno de MVS Noticias con Pamela Cerdeira, el diputado Gustavo Miranda García, en una entrevista en vivo, señaló lo siguiente respecto a la toma: "Aunque ha habido sugerencias de otras dependencias que nos solicitaron que hiciéramos uso de la fuerza pública, no lo hemos hecho"; ante la pregunta directa de qué otras dependencias le habían pedido eso, contestó: "por parte del gobierno estatal y gobiernos municipales" (Cerdeira, 2021).

Las declaraciones del diputado dejaron en claro que no sabía sobre los alcances del ejercicio del derecho a la protesta o que el servicio de luz es parte de las condiciones previas que debían garantizarse, lo cual aceptó al admitir las medidas precautorias y cautelares; seguía sosteniendo que era casi un favor que no usara la fuerza pública para desalojar a las feministas del Congreso y, lo más grave, aseguró que fue el Gobierno del estado de Quintana Roo el que le había pedido que las desaloje del Congreso, lo que demuestra el grado de peligro, riesgo permanente y vulnerabilidad en el que se encontraban como defensoras de derechos humanos. 
Dado que ni el Legislativo ni el Ejecutivo tenían la fuerza ni la voluntad real para solucionar el tema de la reinstalación de la energía eléctrica, el 26 de enero las feministas solicitaron el amparo y la protección de la justicia federal a través de la interposición de un juicio de amparo indirecto en contra del Poder legislativo como autoridad ordenadora y de la CFE como autoridad ejecutora, en virtud de que los cortes al suministro de energía eléctrica y agua representaban una violación al derecho de reunión pacífica y de protesta. El juicio se radicó ante el Juzgado Primero de Distrito, bajo el número de expediente 51/2021-II y el Incidente de Suspensión 51/2021. En virtud del amparo interpuesto, la luz fue reconectada el 4 de febrero de 2021, después de cuarenta y seis días de corte. Al día siguiente fue activada la bomba y se contó con el suministro de agua.

\section{Los murales}

En el marco de la toma pacífica del Congreso, el arte fue otra forma de expresar la rabia y el enojo frente al sistema machista, misógino y patriarcal que rige socialmente; fue otra forma de visibilizar las omisiones del Estado, la complicidad con los agresores y la permisividad de la violencia.

"Forma, color e historia de Quintana Roo" es el título del mural que se encuentra en el vestíbulo del Congreso; entre las escenas que lo componen, hay una en la que se retrata a una mujer en el suelo, con las piernas abiertas, claramente recién violada por el hombre que está de pie frente a ella subiéndose la bragueta. Eso demuestra que la realidad está plagada de violencia hacia las mujeres, siendo lastimoso que los vestigios que existen den cuenta de ello, como si fuera algo digno de plasmar.

En casi todos los momentos de la historia, las mujeres han sido sometidas, violentadas, abusadas; siempre como objetos de cambio y placer. Han sido utilizadas como estandarte político, sólo para los discursos, mientras siguen normalizándose todos los tipos y modalidades de violencia contra las mujeres y siguen siendo omisos sus derechos humanos.

Por ello, durante la toma, en el mes de enero de 2020, desde la Red Feminista Quintanarroense, se convocó a muralistas feministas que quisieran hacer historia y plasmar su arte en el mural que se elaboró al exterior de "la Congresa" - como se denominó al recinto para nombrarla en femeninocomo una contrapropuesta del mural del interior; una obra que demostrara que las mujeres siempre han levantado la voz y exigido el reconocimiento de sus derechos - prueba de ello son los avances y derechos logrados-, 
que demostrara que, durante la toma, las mujeres, feministas, activistas y defensoras de derechos humanos estaban en pie de lucha. Todo ello debe quedar plasmado en los crónicas de la historia del estado pues la fuerza, la resistencia, la firmeza y el espíritu tienen el soporte de todas las mujeres que se sumaron a esa lucha.

\section{El acuerdo}

Finalmente, después de setenta y seis días de toma del Congreso y de muchas negociaciones entre la XVI Legislatura y la RFQ, el 10 de febrero de 2021, se suscribió un acuerdo (Red Feminista Quintanarroense y XVI Legislatura del Congreso del Estado de Quintana Roo, 2021). Los puntos tratados y negociados para integrar al mismo fueron los siguientes:

- La atención de las iniciativas presentadas en relación con los derechos sexuales y reproductivos de las mujeres en Quintana Roo se daría mediante de un nuevo calendario que sería acordado por el Pleno el 15 de febrero de 2021.

- Los procesos relacionados para este fin (foros, sesiones de comisiones, dictaminación y votación en Pleno) comprenderían el periodo del 16 al 24 de febrero de 2021.

- A partir de la firma del acuerdo y hasta la dictaminación de las iniciativas para despenalizar el aborto, la Red Feminista Quintanarroense seguiría en las instalaciones del recinto legislativo, permitiendo el acceso a diputadas, diputados y personal mínimo indispensable del Congreso a los espacios de oficinas administrativas y salón del Pleno.

- La coexistencia entre las integrantes de la RFQ y las personas servidoras públicas del Congreso del Estado se efectuaría de las 9:00 a las 17:00 horas, pudiendo ingresar ellos por la puerta posterior que lleva al estacionamiento.

- Una vez emitido el dictamen, la RFQ efectuaría la desocupación y entrega de las instalaciones del Congreso.

- Las integrantes de la RFQ podrían asistir a la sesión del Pleno en la que se iba a desahogar la discusión y votación del dictamen correspondiente.

- Respecto a las otras nueve acciones legislativas consideradas por la RFQ, se propuso establecer un calendario para su aten- 
ción -el cual abarcaría el año 2021-, en el que se priorizaría y salvaguardaría la construcción de la normatividad en torno a los derechos humanos de las mujeres.

- La XVI Legislatura señalaba que no ejerció ni ejercería persecución, denuncia, procedimientos, señalamientos políticos ni sociales en contra de ninguna persona integrante de la RFQ o que defienda los derechos humanos de las mujeres.

- La comunicación para la observancia y atención de los puntos del acuerdo se llevarían a cabo mediante una comisión integrada por las personas designadas por las y los diputados de la XVI Legislatura y las integrantes de la RFQ.

- Ambas partes aceptaban el atestiguamiento de personal de la ONU-DH México, Servicios y Asesoría para la Paz, A. C. (Serapaz), la Red Violeta por la Paz y la CDHEQROO a manera de acompañantes y observadores.

La suscripción se dio el 10 de febrero de 2021; fue respaldada por Servicios y Asesoría para la Paz, A. C. (Serapaz) (2021) y por la ONU-DH México (Naciones Unidas México, 2021). Ese mismo día fue habilitado nuevamente el internet con acceso libre en el Congreso.

Parte del acuerdo con la XVI Legislatura implicó coexistir o compartir el espacio del vestíbulo hasta que se emitiera el dictamen sobre el derecho a decidir. Por ello, durante el proceso de cambio de calendario, emisión de convocatorias, realización de foros y discusión en Comisiones Unidas, las feministas permanecieron al interior de las instalaciones del Congreso con el riesgo latente que eso significaba.

A efecto de lograr una mejor coexistencia, se efectuó una reducción del espacio en el que ellas mantenían la toma; se estableció una separación física con mamparas para evitar que estuvieran a la vista y fueran objeto de agresiones. En el proceso, se dieron diversas fricciones; sin embargo, ellas fueron pacientes y prudentes con el fin de avanzar en lo que les interesaba: la discusión de las iniciativas a favor de la despenalización del aborto en Quintana Roo.

El 15 de febrero, se sesionó en el salón del Pleno del recinto oficial y se emitió el nuevo calendario para celebrar las audiencias públicas y cumplir el proceso legislativo entre el 16 y el 24 de febrero (Torres, 2021). 
Sin embargo, desde la mañana del sábado 20 de febrero, las integrantes de la RFQ fueron víctimas de diversos ataques. En redes sociales circuló un video criminalizando la lucha y la toma pacífica del Congreso. De igual forma, se publicaron dos notas periodísticas de las que se deduce la intromisión de la Iglesia católica en contra del avance de los derechos sexuales y reproductivos, inmiscuyéndose en asuntos políticos en una clara violación a la normatividad en materia de asociaciones religiosas y cometiendo delitos electorales (Varillas, 2021).

La intromisión se dio a tal grado que el monseñor Pedro Pablo Elizondo hizo la siguiente publicación en Twitter: "Pido a Dios que los diputados de Quintana Roo @CongresoQRoo no sucumban a la presión de grupos agresivos minoritarios olvidando a las mayorías que ellos representan. \#QuintanaRooEsProvida" (Elizondo, 2021). Aunado a ello, en varios puntos de la ciudad de Chetumal y otros municipios del estado, se repartió material impreso con imágenes de la toma y de las compañeras que permanecían en ella, incentivando el discurso de odio e intolerancia en su contra como defensoras de derechos humanos. Sin duda, el efecto logrado por las manifestantes fue grande: que las y los diputados modificaran el calendario de discusión.

Gracias a los compañeros y compañeras de los medios de comunicación, se dio a conocer que, a través de grupos de WhatsApp, circulaba la siguiente convocatoria:

Ciudadanos rechazan que el Congreso de Quintana Roo siga siendo vandalizado por feministas.

Este lunes 22 de febrero, a las 17:00, mujeres y hombres de buena voluntad invitan a la prensa local a una actividad que busca contribuir a una cultura de paz y vida.

El pueblo de Quintana Roo ha sido lastimado por la inacción de las autoridades. Por esta razón, buscan dar un mensaje: en las peores crisis, los pueblos salen adelante si la gente se activa y lucha por la verdad.

El hijo no nacido es persona y tiene derechos humanos. Estos colectivos pretenden disminuir la protección del derecho a la vida, ya que detrás del aborto hay una agenda internacional que busca lucrar con la sangre de los mexicanos no nacidos. 
El pueblo de Chetumal está cansado de tanta impunidad. Ellos buscarán visibilizar que no hay condiciones que garanticen un proceso legislativo neutro y justo.

Las feministas rompen, pintan, queman y secuestran instituciones. El gobierno federal y local promueven la impunidad y es el pueblo quien tiene que exigir se respete el marco jurídico.

Te esperamos este lunes a las 17:00 horas en el Congreso de Quintana Roo para hacer el trabajo que el gobierno dejó de hacer: fortalecer el Estado de derecho. (R. Pedraza, Comunicación personal, 20 de febrero de 2021)

Esta convocatoria representaba un llamado a la agresión. Dado que la RFQ ya estaba incorporada al Mecanismo Nacional para la Protección de Personas Defensoras de Derechos Humanos de la Secretaría de Gobernación, la noche del 21 de febrero de 2021, solicitaron que, como una labor prioritaria e inmediata, el Gobierno federal en coordinación con el ejecutivo del estado de Quintana Roo emprendieran una acción para minimizar el efecto de la criminalización y escrutinio público al que se les había sometido a quienes sostenían la toma, emitieran las instrucciones necesarias para que, a través de los cuerpos policiacos a su cargo, se detuviera la distribución y difusión del material elaborado en su contra y se iniciaran las investigaciones correspondientes a nivel estatal contra quienes lo estuvieran financiando. De igual manera, solicitaron que se reforzaran los mecanismos de seguridad en las instalaciones del Congreso los siguientes días, en los que se daría la discusión en Comisiones Unidas y la votación en el Pleno.

Respecto a los ministros de las asociaciones religiosas que incurrieron en delitos flagrantes, se solicitó a las autoridades a nivel nacional que procedieran legalmente, de acuerdo con el artículo 25 de la Ley de Asociaciones Religiosas y Culto Público (Cámara de Diputados del H. Congreso de la Unión, 1992), cuya aplicación corresponde a la Secretaría de Gobernación federal.

El 22 de febrero de 2021, las feministas que sostenían la toma convocaron a una rueda de prensa para señalar a las personas responsables de incentivar el mensaje de odio e intolerancia hacia las manifestantes como defensoras de derechos humanos; entre esas personas estaba monseñor Pedro Pablo Elizondo (Marea Verde Quintana Roo, 2021d). 
Dado que, según el calendario, el proceso de foros, discusión y dictaminación, así como de votación de las iniciativas concluiría el 24 de febrero, la RFQ convocó a las compañeras afines a la lucha para concentrarse a las afueras del Congreso del estado durante los días 22, 23 y 24 de febrero, por lo que pidieron que se reforzara la seguridad del área y solicitaron que se establecieran vallas para controlar el ingreso. Sin embargo, no fueron proporcionadas.

Como estaba previsto en su convocatoria, el 22 de febrero de 2021, los antiderechos intentaron acercarse a los murales exteriores para pintarlos, pero no lo lograron, en virtud de que las compañeras convocadas se instalaron alrededor de los mismos. Sin embargo, la mañana del 23 de febrero de 2021, los murales - que se habían elaborado al exterior del Congreso para manifestar la digna rabia ante la violencia de género que las mujeres vivimos en todos los espacios- amanecieron pintados de blanco; se deduce que este acto se efectuó durante la madrugada, a pesar de la presencia del personal policiaco y del personal de vigilancia del Congreso del estado (Marea Verde Quintana Roo, 2021c).

Este hecho llevó a convocar a más muralistas; respondieron al llamado feministas locales, nacionales e internacionales que colaboraron diseñando y pintando nuevos murales, así como recuperando los que habían sido afectados. Durante el evento, un ministro de la Iglesia católica se atrevió a acercarse al espacio donde las compañeras estaban pintando y quiso imponer sus ideas (Siempre Unidas, 2021) A tal grado llegó la osadía de los integrantes de los cuerpos eclesiásticos en Quintana Roo, quienes no recibieron ni han recibido sanción alguna por involucrarse en cuestiones políticas e incidir en la forma en la que las y los diputados deberían votar.

\section{Opiniones técnicas y foros}

Mientras tanto, la XVI Legislatura recibió, vía correo electrónico, diversas opiniones técnicas y cartas de apoyo a favor de la despenalización del aborto; las instituciones marcaron copia al correo de la Red Feminista Quintanarroense, razón por la que se pudo acceder al contenido y conocer las fechas en las que fueron remitidas a las y los legisladores. Los documentos fueron suscritos por organizaciones internacionales e instituciones nacionales; entre ellas: 
a. Centro Nacional de Equidad de Género y Salud Reproductiva

b. Instituto Nacional de Psiquiatría Ramón de la Fuente

c. Comité de América Latina y el Caribe para la Defensa de los

Derechos de las Mujeres (CLADEM)

d. Consejo Nacional de Población (CONAPO)

e. Comisión Nacional para Prevenir y Erradicar la Violencia contra las Mujeres (Conavim)

f. Instituto Nacional de las Mujeres (INMUJERES)

g. Red de Salud de las Mujeres Latinoamericanas y del Caribe (RSMLAC)

h. Red Latinoamericana y del Caribe de Católicas por el Derecho a Decidir (Red LAC de CDD)

i. Iniciativas Sanitarias Uruguay

Asimismo, durante los foros que se efectuaron, se emitieron argumentos médicos, legales, convencionales, científicos y éticos para despenalizar el aborto. De igual manera, las instancias federales y organizaciones internacionales, en sus opiniones técnicas y cartas de apoyo a las iniciativas, señalaron los criterios sostenidos por la Suprema Corte de Justicia de la Nación (SCJN), las convenciones y las observaciones señaladas al Estado mexicano por los comités de seguimiento a los tratados internacionales de los que México es parte.

\section{La Sesión de Comisiones Unidas}

El 24 de febrero de 2021, se efectuó la Sesión de Comisiones Unidas con las y los integrantes de las cinco comisiones a las que se remitieron las dos últimas iniciativas sobre el tema (Puntos Constitucionales, Justicia, Salud, Derechos Humanos e Igualdad de Género).

Después de diez horas con cuatro recesos, el dictamen no fue emitido en virtud de que un diputado del Partido Acción Nacional (PAN) - que no pertenecía a ninguna de las comisiones a las que fueron remitidas las iniciativas-, dos diputadas del PAN, un diputado del Partido Revolucionario Institucional (PRI) y una diputada independiente interpusieron una serie de obstáculos para tratar de retrasar la discusión y, en el caso de que se lograra una dictaminación a favor, evitar que fuera aprobada en el Pleno al tratar de incluir en el dictamen lo relativo a la reforma constitucional. Finalmente, 
al ver que no lograrían su objetivo, se fueron de la sesión para romper el quorum (Congreso del Estado de Quintana Roo, 2021d).

Es necesario mencionar que los grupos antiderechos se concentraron en la parte posterior del Congreso, en donde se ubica el estacionamiento, y hubo momentos en los que se aproximaron demasiado a las compañeras que se encontraban restaurando los murales que habían sido afectados.

Al no haberse dado la dictaminación en el periodo pactado en el acuerdo suscrito entre la XVI Legislatura y la RFQ, el 25 de febrero de 2021, las manifestantes volvieron a tomar la totalidad de las instalaciones del Congreso y emitieron el siguiente comunicado:

El 10 de febrero firmamos un acuerdo entre la Red Feminista Quintanarroense y el Congreso del Estado de Quintana Roo, representado por los presidentes y presidentas de las cinco comisiones que atienden el paquete de iniciativas sobre los derechos sexuales y reproductivos, y la Junta de Gobierno y Coordinación Política, donde con claridad enfatizamos que íbamos a retirarnos de las instalaciones del Congreso del estado a la entrega de un dictamen de dichas iniciativas, teniendo como fecha límite el 24 de febrero del presente año.

Lo lamentable es que el día de ayer, como lo vieron las y los miles de quintanarroenses, se incumplió dicho acuerdo, al intervenir de manera alevosa, y entorpeciendo el trabajo de las comisiones unidas el diputado Eduardo Martínez Arcila, así como las diputadas Reyna Durán Ovando, Kira Iris San, Aurora Pool Cahuich y el diputado Carlos Hernández Blanco, quienes le siguieron el juego a un diputado que por sí mismo no pertenecía a dichas comisiones y que además ingresó a esta legislatura por vía plurinominal.

Lo que vimos ayer las y los quintanarroense fue muy lamentable para las y los ciudadanos que confiamos en nuestros representantes.

De todo esto, queremos señalar como responsable al gobernador del estado de Quintana Roo, Carlos Joaquín González, quién a través de sus operadores, el diputado Eduardo Martínez Arcila y Carlos Hernández Blanco, utilizando diversas artimañas retrasaron la votación del dictamen respectivo.

A razón de ello, nos levantamos de nueva cuenta de las mesas de trabajo con el Ejecutivo estatal, puesto que no hay duda de que hubo intervención directa de quien hoy es el jefe político de estos diputados. 
Es importante recalcar que el dictamen iba a ser aprobado en comisiones, en consecuencia, para que ello no pasara, decidieron obstaculizar el trabajo de las y los diputados que iban a votar a favor, rompiendo el quorum en diversos momentos.

Dentro de algunos de los argumentos que dieron pie a estos intensos debates, fue la razón de incluir o no la reforma al artículo 13 constitucional. Queremos señalar que la intención de incluir la reforma a la Constitución en el proyecto de dictamen, lo único que buscaba por parte de estos diputados y diputadas era retrasar y evitar que se aprobara el dictamen por mayoría simple en el Pleno, dado que una reforma constitucional requiere no sólo las tres cuartas partes de las y los diputados que integran el mismo, sino que requiere, aunado a ello, la aprobación en la mayoría de los municipios del Estado, cosa que empantanaría el logro de la reforma en materia de derechos sexuales y reproductivos de las mujeres.

Por otra parte, es importante recalcar que dichos diputados en todo momento antepusieron sus intereses políticos a los argumentos médicos, científicos y legales, como las sentencias de la Corte Interamericana de Derechos Humanos y los criterios de la Suprema Corte de Justicia de la Nación, así como las opiniones técnicas emitidas por las autoridades internacionales y federales.

Asimismo, dentro del proceso legislativo se contempló la realización de seis foros de consulta donde se plantearon argumentos técnicos y jurídicos a favor de los derechos sexuales y reproductivos, donde ninguno de estos diputados y diputadas asistió y/o cuestionó los contenidos de las iniciativas.

De igual forma, lamentamos que sea la Comisión de Igualdad, en donde se supone se debe velar por los derechos humanos de las mujeres, donde más observamos deserciones, pues la diputada Atenea Gómez Ricalde y la diputada Lily Campos Miranda no quisieron asumir el costo político que implicaba legislar a favor de las mujeres, y en cambio privilegiaron sus intereses políticos y electorales.

Pese a todo lo anterior, queremos agradecer a los diputados y diputadas que permanecieron en la sesión con el objetivo de trabajar a favor de los derechos humanos. En especial, Judith Rodríguez Villanueva, Edgar Gasca Arceo, Tyara Schleske, Erika Castillo, Hernán 
Villatoro, Iris Mora Vallejo, José Luis Guillen, José de la Peña, y Ana Pamplona.

Asimismo, agradecemos a la dirección de análisis jurídico por el profesionalismo que demostraron en la elaboración del proyecto de dictamen a favor de los derechos sexuales y reproductivos de las mujeres; lamentamos la incapacidad de las y los diputadas del PAN y el PRI al querer retrasar la votación de dicho dictamen, sin argumentos sostenibles.

Agradecemos a las cientos de mujeres que nos acuerparon el día de ayer en el Congreso del estado, y a las y los miles de ciudadanos que a través de las redes sociales nos respaldaron y dieron seguimiento al trabajo de las comisiones unidas. Sin ustedes esta lucha no sería posible.

Recalcamos que seguimos abiertas al diálogo y a la suscripción de un nuevo acuerdo, pero requerimos una nueva interlocución que sea a nivel nacional, ya que se han agotado todas las instancias estatales, y hemos visto que incluso quien dice y debería protegernos, el día de ayer operó de manera directa en contra las mujeres defensoras de derechos humanos. (Marea Verde Quintana Roo, 2021b)

De esa manera, seguían firmes en su objetivo. El 1 de marzo, se emitió un comunicado conjunto (Marea Verde Quintana Roo, 2021a), en el que se señalaba que, después de un diálogo entre la XVI Legislatura y la RFQ, con la interlocución de personal de la $\mathrm{CNDH}$, se había acordado que, el martes 2 de marzo, ambas partes suscribirían un adendum que establecía que ese mismo día se reanudaría la sesión de las Comisiones Unidas a cargo del análisis, discusión y dictaminación de las iniciativas en relación con los derechos sexuales y reproductivos de las mujeres. Dicho adendum fue atestiguado por personal de la ONU-DH México, de la CNDH y de la CDHEQROO, a manera de acompañantes y observadores del cumplimiento del mismo.

Así, el 2 de marzo, se reanudó la sesión de Comisiones Unidas; el dictamen emitido fue a favor de la despenalización y de efectuar las reformas propuestas para garantizar el derecho a decidir sin ser criminalizadas y asegurar el servicio de la interrupción en los centros de salud del estado (Congreso del Estado de Quintana Roo, 2021a).

Tal como se había acordado en el adendum, la RFQ, ya con un dictamen aprobado, abandonó las instalaciones del Congreso y acampó a las 
afueras de éste, a la espera de la sesión del Pleno en la que se votaría el dictamen, la cual se realizó ese mismo día. La convocatoria se había realizado para ir a acuerpar todo ese día y hasta que se efectuara la discusión en el Pleno por lo que había un grupo considerable de mujeres a la expectativa de la resolución.

\section{La votación en el Pleno del Congreso}

El dictamen en sentido positivo antes referido fue leído en la Sesión número 6 del Segundo Periodo Ordinario de Sesiones del Segundo Año de Ejercicio Constitucional del Congreso del Estado de Quintana Roo el 2 de marzo de 2021, estando la XVI Legislatura en Pleno (Congreso del Estado de Quintana Roo, 2021b). En dicha sesión, se contó inicialmente con la asistencia de veintidós, después de veintitrés y finalmente de veinticuatro legisladores y legisladoras del total de veinticinco - a la sesión faltó únicamente la diputada del Partido Verde Ecologista de México-.

Al someter el dictamen a votación, sólo votaron veinte legisladores y legisladoras, puesto que cuatro -Wilbert Alberto Batún Chulim, Luis Fernando Chávez Zepeda, María Fernanda Trejo Quijano y Chanito Toledo Medina - se retiraron de la sesión para evitar votar, sin que se haya levantado constancia de ello durante la sesión.

De quienes sí permanecieron en la sesión y votaron, se obtuvieron siete votos a favor del dictamen y trece en contra, por lo que se acordó el desechamiento del "Dictamen con minuta de proyecto de Decreto por el que se reforma el párrafo primero del artículo 13 de la Constitución Política del Estado Libre y Soberano de Quintana Roo; y por el que se reforman diversas disposiciones del Código Penal para el Estado Libre y Soberano de Quintana Roo y se reforman y adicionan diversas disposiciones de la Ley de Salud del Estado de Quintana Roo".

Ninguno de los o las diputadas que emitieron voto negativo fundaron, motivaron o hicieron argumentación legal que justificara su votación en contra del reconocimiento de los derechos sexuales y reproductivos de las mujeres en la entidad, específicamente respecto al derecho a decidir, ni desvirtuaron las opiniones técnicas, los argumentos científicos, médicos, legales y lógicos que se expusieron en los foros de discusión o, en su caso, los que se sostenían en el dictamen que votaron.

Por ello, se interpusieron cuatro amparos indirectos ante los Juzgados de Distrito de la ciudad de Chetumal; éstos tuvieron como objetivos: 
1. La reposición del procedimiento dado que todo acto de autoridad (como lo es el desechamiento de un dictamen) debe estar debidamente fundado y motivado, y ninguna de las legisladoras o legisladores que votaron en contra fundaron ni motivaron su voto en sentido negativo. Es necesario reponer el procedimiento de la votación dado que votaron en contra de la progresividad de los derechos sexuales y reproductivos, lo que violenta el bloque de constitucionalidad que se compone por los derechos humanos contenidos en la Constitución, la jurisprudencia generada por el Poder Judicial federal, los tratados internacionales en materia de derechos humanos de los que México forma parte, el Pacto de San José (Convención Americana sobre Derechos Humanos), los protocolos adicionales a la misma, otros instrumentos internacionales que han sido incorporados a la Convención y la jurisprudencia de la Corte Interamericana de Derechos Humanos que la interpreta.

2. La declaración de la omisión legislativa en la que incurrieron las diputadas y diputadas puesto que ésta se configura cuando el legislador no expide una norma o un conjunto de normas estando obligado a ello por la Constitución (Bazán, 2014, p. 97). En esa línea argumentativa, la Primera Sala de la SCJN ha resuelto que sólo habrá una omisión legislativa propiamente dicha cuando exista un mandato constitucional que establezca de manera precisa el deber de legislar en un determinado sentido y esa obligación haya sido incumplida total o parcialmente (Poder Judicial de la Federación. Suprema Corte de Justicia de la Nación, 2018) y, en ese sentido, al votar en contra de los principios que establece la Constitución y el control convencional mismo.

3. La declaración de la inconstitucionalidad de la prohibición de la interrupción legal del embarazo (ILE) en el Código Penal del Estado de Quintana Roo, al violentar el artículo 1 de la Constitución Política de los Estados Unidos Mexicanos y restringir el derecho humano a la salud previsto en el artículo 4 constitucional; además de las faltas a los artículos 1 y 2 de la Convención Americana sobre Derechos Humanos, el artículo 7, incisos e, f y g, de la Convención de Belém do Pará, los artículos 12, 14, inciso 
b, y 24 de la Convención sobre la Eliminación de Todas las Formas de Discriminación contra la Mujer (CEDAW).

4. Se emita sentencia concediendo el amparo y protección de la Justicia de la Unión para efectos de ordenar a las autoridades demandadas que: i) se abstengan de aplicar en perjuicio de las personas quejosas el artículo 13 de la Constitución Política del Estado Libre y Soberano de Quintana Roo, los artículos 92, 93, 94 y las fracciones II y III del artículo 97 del Código Penal para el Estado Libre y Soberano de Quintana Roo, y se aplique a nuestro favor el artículo 62 la Ley de Salud del Estado de Quintana Roo; ii) se abstengan de imponer cualquier tipo de sanción penal en contra de las personas quejosas por ejercer, cuando así lo deseemos, nuestros derechos sexuales y reproductivos a través de la interrupción del embarazo; y iii) otorguen a las personas quejosas cuando así lo requieran la atención de salud emergente a través de los servicios de salud públicos para la interrupción del embarazo.

Todos ellos siguen en trámite y se continuarán hasta las últimas instancias puesto que, si bien la toma pacífica no fue una acción planeada, una vez efectuada, el objetivo era lograr el acto jurídico que las llevara a poder iniciar las acciones jurisdiccionales necesarias para exigir el respeto, la garantía y la protección de su derecho a decidir.

\section{Conclusiones}

La firmeza de la lucha feminista en Quintana Roo representa un hecho histórico en la lucha por la despenalización del aborto, al haber resistido noventa y cinco días en una toma pacífica del Congreso a pesar de las represiones y el discurso de odio e intolerancia que fue incentivado por las autoridades del estado.

Haber logrado que el Gobierno del estado, la Comisión de los Derechos Humanos del Estado de Quintana Roo, la Organización de las Naciones Unidas en México y el Mecanismo Nacional de Protección de Defensoras de Derechos Humanos emitieran un reconocimiento del movimiento y además exigieran el respeto a su integridad fue determinante.

Obtener las cartas y posicionamientos de organizaciones e instituciones nacionales e internacionales en las que se recomendó una discusión basada 
en los avances científicos y en la objetividad respecto al aborto seguro, legal y gratuito, así como la realización de los foros fue fundamental para evidenciar la forma en la que las y los legisladores que votaron en contra del dictamen sólo emitieron su voto basados en sus creencias religiosas, conveniencias partidistas y su indiferencia hacia la ciudadanía que los llevó a esos escaños.

El dictamen emitido en sentido positivo, debidamente fundado y motivado, contrasta con la falta de argumentos fundados y motivados por parte de las y los diputados que votaron en contra, lo que originó los cuatro amparos que siguen en trámite y a los que se les dará continuidad.

La lucha sigue desde distintas trincheras. La Red Feminista Quintanarroense y quienes la integran seguirán firmes en la causa. No claudicarán hasta que el aborto sea legal, seguro y gratuito.

\section{Referencias bibliográficas}

Bazán, V. (2014). Control de las omisiones inconstitucionales e inconvencionales. Recorrido por el derecho y la jurisprudencia americanos y europeos. Fundación Konrad Adenauer.

Briceño, R. (2021, 12 de enero). "Queremos acciones, no simulaciones": Ante omisión e incumplimiento de diputados, inunda la Red Feminista Quintanarroense transmisión de la sesión solemne de promulgación de la Constitución de QR. Noticaribe. https://noticaribe. com.mx/2021/01/12/queremos-acciones-no-simulaciones-ante-omision-e-incumplimiento-de-diputados-inunda-la-red-feminista-quintanarroense-transmision-de-la-sesion-solemne-de-promulgacion-de-la-constitucion-de-qr/

Cámara de Diputados del H. Congreso de la Unión (1992, 15 de julio). Ley de Asociaciones Religiosas y Culto Público. Diario Oficial de la Federación. https://www.diputados.gob.mx/LeyesBiblio/ref/larcp.htm

Carrasco Fuentes, F. (2021, 5 de enero). Destaca Marea Verde Quintana Roo la apertura al diálogo de Carlos Joaquín. Quinta Fuerza. https:// quintafuerza.mx/quintana-roo/destaca-marea-verde-quintana-roo-la-apertura-al-dialogo-de-carlos-joaquin/

Cerdeira, P. (2021, 20 de enero). Programa completo MVS Noticias con Paloma Cerdeira 20 de enero 2021 [Podcast]. Spotify. https://open. spotify.com/episode/0AAjz0mpXNoY5ze92Gf3yM

Congreso del Estado de Quintana Roo [@CongresoQRoo]. (2021a, 2 de marzo). Reanudación de la reunión de Comisiones Unidas (02/ 
marzo/2021) [Video]. Facebook. https://www.facebook.com/CongresoQRoo/videos/727887944538444/

Congreso del Estado de Quintana Roo [@CongresoQRoo]. (2021b, 2 de marzo). Sesión número 6 del Segundo Periodo Ordinario. (02/ marzo/2021) [Video]. Facebook. https://www.facebook.com/CongresoQRoo/videos/765241197448457/

Congreso del Estado de Quintana Roo [@CongresoQRoo]. (2021c, 24 de febrero). Reunión de Comisiones Unidas (24/febrero/2021) [Video]. Facebook. https://www.facebook.com/CongresoQRoo/ videos/336500747687857

Congreso del Estado de Quintana Roo [@CongresoQRoo]. (2021d, 24 de febrero). Reanudación de las Comisiones Unidas (24/febrero/2021) [Video]. Facebook. https://www.facebook.com/CongresoQRoo/ videos/74224650634472

Congreso del Estado de Quintana Roo (2020, 9 de diciembre). Reunión de la Comisión de Derechos. (9/diciembre/2020) [Video]. Facebook. https:// www.facebook.com/CongresoQRoo/videos/389928258890098/

Consejo Consultivo de la CDHEQROO (2020). Comunicado 41/2020. Consejo Consultivo de la CDHEQROO a favor de reconocer y legislar sobre derechos sexuales y reproductivos de las mujeres. Derechos Humanos Quintana Roo. http://www.derechoshumanosqroo.org. $\mathrm{mx} /$ portal/portal/ApoyoDifusion/cc/comunicado41.pdf

El Quintana Roo MX (2020, 2 de diciembre). La XVI Legislatura designó al Centro de Convenciones de Chetumal como sede alterna para sesionar. El Quintana Roo MX. https://elquintanaroo.mx/la-xvi-legislatura-designo-al-centro-de-convenciones-de-chetumal-como-sede-alterna-para-sesionar/

Elizondo, P. P. [@PedroPablObispo] (2021, 20 de febrero). Pido a Dios que los diputados de Quintana Roo @CongresoQRoo no sucumban a la presión de grupos agresivos minoritarios [Perfil de Twitter]. Twitter. https:// twitter.com/PedroPablObispo/status/1363203750756814848

EquilibrioDigital (2021, 12 de enero). Segunda llamada de Carlos Joaquín a diputados para atender demandas de grupos feministas. Equilibrio Quintana Roo. https://www.equilibrioquintanaroo.com/post/segunda-llamada-de-carlos-joaqu\%C3\%ADn-a-diputados-para-atender-demandas-de-grupos-feministas

Gobierno de Quintana Roo (2020, 15 de diciembre). El gobernador Carlos 
Joaquín se reunió con la Red Feminista de Quintana Roo, para ofrecer soluciones al pliego petitorio. https://qroo.gob.mx/portalanterior/ el-gobernador-carlos-joaquin-se-reunio-con-la-red-feminista-de-quintana-roo-para-ofrecer-soluciones-al-pliego-petitorio/

Lagarde, M. (2006). Pacto entre mujeres. Sororidad. Aportes para el Debate, 25, 123-135. https://www.asociacionag.org.ar/pdfaportes/25/09. pdf

Maldonado, J., Ruiz, R. y Ramírez, A. (2020, 26 de noviembre). Feministas anuncian plantón para que diputados retomen el tema del aborto. La Jornada Maya. https://lajornadamaya.mx/pdf/LJM-QRoo-26112020. pdf

Marea Verde Quintana Roo [@MareaVerdeQuintanaRoo].(2021a,1 de marzo). Comunicado 01-03-21. Red Feminista Quintanarroense [Publicación]. Facebook. https://www.facebook.com/MareaVerdeQuintanaRoo/ posts/927599497991207

Marea Verde Quintana Roo [@MareaVerdeQuintanaRoo]. (2021b, 25 de febrero). Comunicado RFQ 25 feb [Video]. Facebook. https://www. facebook.com/MareaVerdeQuintanaRoo/videos/252113723283009/

Marea Verde Quintana Roo [@MareaVerdeQuintanaRoo]. (2021c, 23 de febrero). Hoy nos despertamos con nuestros murales [...] manchados de blanco [Publicación]. Facebook. https://www.facebook.com/330311867719976/ posts/923949205022903/

Marea Verde Quintana Roo [@MareaVerdeQuintanaRoo]. (2021d, 22 de febrero). RFQ denuncia criminalización y ataques de odio. Señala agresores directamente [Video]. Facebook. https://www.facebook. com/MareaVerdeQuintanaRoo/videos/423893508912209/

Milenio Digital (2020, 16 de noviembre). Bianca Alexis tenía miedo de ser asesinada; la hallaron muerta en Cancún un día después de desaparecer. Milenio. https://www.milenio.com/estados/bianca-alexis-feminicidio-en-cancun-asi-ocurrio

Miranda, G. [@GusMirandag] (2021a, 18 de enero). [Sobre la toma del Congreso] [Video]. Facebook. https://www.facebook.com/GusMirandag/videos/228385985495757

Miranda, G. [@GusMirandag] (2021b, 15 de enero). Tema Acuerdo Feministas. Comenta qué harías tú con la situación de la luz en el Congreso [Video]. Facebook. https://www.facebook.com/GusMirandag/videos/ 407681983674308/ 
Naciones Unidas México (2021, 11 de febrero). ONU-DH saluda el Acuerdo entre la XVI Legislatura del Congreso de Quintana Roo y la Red Feminista Quintanarroense. https://www.onu.org.mx/onu-dh-saluda-el-acuerdo-entre-la-xvi-legislatura-del-congreso-de-quintana-roo-y-la-red-feminista-quintanarroense/

ONU-DH México [@ONUDHmexico] (2020, 22 de diciembre). Las manifestaciones y protestas son aspectos esenciales de la democracia [Hilo]. Twitter. https://twitter.com/ONUDHmexico/status/1341508205336174594

Palco Noticias (2020, 17 de noviembre). Entrega Red Feminista pliego petitorio con 54 puntos a Carlos Joaquín. Palco Noticias. https://www. palcoquintanarroense.com.mx/noticias-de-quintana-roo/cancun/ entrega-red-feminista-pliego-petitorio-con-54-puntos-a-carlos-joaquin/

Poder Judicial de la Federación. Suprema Corte de Justicia de la Nación (2018). Tesis Aislada y, en su caso, ejecutorias. Omisiones legislativas. Su concepto para fines del juicio de amparo. Gaceta del Semanario Judicial de la Federación, Décima Época, libro 52, tomo I, p. 1100. https://www.scjn.gob.mx/sites/default/files/gaceta/documentos/ tomos/2018-04/Libro52t1.pdf

Red Feminista Quintanarroense (2021). Oficio a AMLO. Pliego y cronología de hechos. Ciudad de México. SEM México. Servicio Especial de la Mujer. https://www.semmexico.mx/wp-content/uploads/2021/01/ Oficio-a-AMLO-pliego-y-cronologia-de-hechos.pdf

Red Feminista Quintanarroense (2020, 19 de diciembre). La Red Feminista Quintanarroense solicita a la CNDH medidas precautorias y cautelares [Video]. YouTube. https://www.youtube.com/watch?v=P561OA3XhV4

Red Feminista Quintanarroense y XVI Legislatura del Congreso del Estado de Quintana Roo (2021, 11 de febrero). Acuerdo entre la Red Feminista Quintanarroense y Congreso de Quintana Roo. Serapaz. https:// serapaz.org.mx/acuerdo-entre-red-feminista-y-congreso-de-quintana-roo/

Ruíz, J. F. (2017). Los órganos constitucionales autónomos en México: Una visión integradora. Cuestiones constitucionales, (37), 85-120. https:// doi.org/10.22201/iij.24484881e.2017.37.11454

Servicios y Asesoría para la Paz, A. C. (2021, 11 de febrero). Acuerdo entre la Red Feminista Quintanarroense y Congreso de Quintana Roo. Serapaz. 
https://serapaz.org.mx/acuerdo-entre-red-feminista-y-congreso-de-quintana-roo/

Siempre Unidas [@siempreunidasPlaya]. (2021, 23 de febrero). [Provocación de la Iglesia a feministas] [Video]. Facebook. https://www.facebook. com/siempreunidasPlaya/videos/247046450295608/

Torres, R. (2021, 15 de febrero). Este lunes se votará calendario para debatir aborto en Congreso. Luces del Siglo. https://lucesdelsiglo. com/2021/02/15/este-lunes-se-votara-calendario-para-debatir-aborto-en-congreso-local/

Varillas, A. (2021, 19 de febrero). Obispo mete presión a políticos que se pronuncien a favor de despenalizar el aborto en Quintana Roo. EstamosAqui.mx. https://estamosaqui.mx/2021/02/19/obispo-mete-presion-a-politicos-que-se-pronuncien-a-favor-de-despenalizar-el-aborto-en-quintana-roo/

Varillas, A. (2020, 17 de noviembre). Red Feminista presenta pliego de demandas al gobernador de Quintana Roo. El Universal. https:// www.eluniversal.com.mx/estados/red-feminista-presenta-pliego-de-demandas-al-gobernador-de-quintana-roo 